\title{
Urinary steroid concentrations during natural and gonadotrophin-induced oestrus and pregnancy in the giant panda (Ailuropoda melanoleuca)
}

\author{
M. Chaudhuri*†, D. G. Kleiman $\ddagger$, D. E. Wildt $\ddagger$, M. Bush $\ddagger$, E. S. Frank $\ddagger$ \\ and R. B. Thau $†$
}

* $\uparrow$ New York Zoological Society, Bronx, NY 10460, U.S.A.; †Center for Biomedical Research, The Population Council, New York, NY 10021, U.S.A.; and $\$$ National Zoological Park, Smithsonian Institution, Washington, DC 20008, U.S.A.

\begin{abstract}
Summary. Urinary concentrations of conjugated oestrone and pregnanediol-3-glucuronide were measured during and after spontaneous and induced oestrus and during pregnancy. Behavioural oestrus was preceded by a rise in oestrone values from $<10 \mathrm{ng}$ / $\mathrm{mg}$ creatinine $(\mathrm{Cr})$ to peaks of $45 \mathrm{ng} / \mathrm{mg} \mathrm{Cr}$. Maximal lordotic response and mating activity coincided with the decline in oestrone levels. After presumed ovulation, urinary pregnanediol glucuronide concentrations increased from $<5$ to $15-30 \mathrm{ng} / \mathrm{mg} \mathrm{Cr}$. Further increases in this steroid (to $60-80 \mathrm{ng} / \mathrm{mg} \mathrm{Cr}$ ) occurred 114 days after mating, presumably coincident with implantation. These high levels of pregnanediol glucuronide were maintained for 3 weeks, began to decline 1 week before parturition and fell to a nadir $(<5 \mathrm{ng} / \mathrm{mg} \mathrm{Cr}$ ) immediately after delivery. When FSH was administered i.m. for 5 days, urinary oestrone values rose markedly and were maximal ( $580 \mathrm{ng} / \mathrm{mg} \mathrm{Cr}$ ) on Day 7. Mating first occurred on Day 20 and 500 i.u. hCG were given i.m. Urinary pregnanediol glucuronide levels during the next 5 months were similar to those in the previous year during pregnancy with values rising 105-108 days after mating. However, no birth occurred. These results support the suggestion that pandas exhibit delayed implantation and demonstrate that the panda is responsive to exogenous gonadotrophins.
\end{abstract}

Keywords: giant panda; reproductive cycle; ovulation induction; oestrone; pregnanediol

\section{Introduction}

The giant panda (Ailuropoda melanoleuca) is an endangered species, numbers of which in the wild are decreasing at an alarming rate. Therefore, great efforts should be made to learn enough about the reproductive biology of this animal to assure successful breeding in captivity. Giant pandas are known to be seasonally monoestrous (Anon, 1974; Schaller et al., 1985) and may show delayed implantation (Hodges et al., 1984). The latter observation was made in one animal by measuring the concentrations of pregnanediol-3-glucuronide (a progesterone metabolite) in urine. The concentration of this hormone increased 120 days after the animal was artificially inseminated and stayed elevated until parturition. We have now measured urinary steroid concentrations in another giant panda over a 3 -year period.

\section{Materials and Methods}

Animal. The 12-year-old giant panda at the National Zoological Park in Washington, DC was studied over a 4-year period. The male and the female were housed separately with the opportunity to interact through steel mesh fences. 
Introductions were made only during the time of behavioural oestrus. The animals were monitored continuously by closed-circuit television so that mating could be scored accurately. The behavioural observations were described by trained voluntary observers according to the methods described by Kleiman et al. (1979). Similarly, a panda pregnancy watch was initiated near the approximate time of delivery based on hormone patterns.

Urine samples were obtained by aspiration from the cage floor every morning. The samples were frozen, shipped in solid $\mathrm{CO}_{2}$ to New York and kept at $-20^{\circ} \mathrm{C}$ until analysed.

Steroid assays. All the steroid values reported are expressed relative to urinary creatinine (Cr) concentrations. The urine was most often diluted with the animal's drinking water and the Cr levels obtained were below the sensitivity of the assay $(0.1 \mathrm{mg} / \mathrm{ml}$ urine). The usual procedure in such cases has been to discard the samples. However, since these samples were so valuable, alternative methods had to be developed. For this reason, the urine was lyophilized and then reconstituted in distilled water so that the levels of $\mathrm{Cr}$ were measurable. Initially, all samples were checked for $\mathrm{Cr}$ and those that had low $\mathrm{Cr}$ levels were lyophilized. Since this was found to be true for the majority of the samples, all the samples were lyophilized as a routine procedure. Urine was usually concentrated to $\sim 4$-fold its original concentration. Lyophilization did not affect the creatinine or steroid levels as determined by adding exogenous amounts of these compounds to the urine and measuring the amounts before and after lyophilization. The procedure of Taussky (1954) was used to measure Cr. All assay validations were done on lyophilized urine samples.

To assess oestrogen concentrations in the giant panda, conjugated oestrone was measured by radioimmunoassay as described by Shideler et al. (1983): $50 \mu \mathrm{l}$ of urine were combined with $150 \mu \mathrm{l} 0 \cdot 1 \mathrm{M}$-Tris buffer $\mathrm{pH} 8 \cdot 4(0.9 \% \mathrm{w} / \mathrm{v} \mathrm{NaCl}$, $0.1 \%$ sodium azide, $0.1 \%$ gelatin) and this was incubated with $100 \mu \mathrm{l}$ oestrone glucuronide antiserum (dilution $1: 7500$ ). The cross-reactivity of this antiserum with various conjugated and non-conjugated oestrogens using oestrone sulphate as the tritiated standard (sp. act. $40 \mathrm{Ci} / \mathrm{mmol}$; New England Nuclear, Boston, MA, U.S.A.) were: $110 \%$ with oestrone glucuronide, $120 \%$ with oestrone, $2.2 \%$ with oestradiol and $<0 \cdot 1 \%$ with oestradiol-3-sulphate-17 $\beta$-glucuronide, oestradiol-3-sulphate, oestriol and oestriol-16a-glucuronide. Serial dilutions of panda urine gave displacement curves parallel to that obtained with increasing amounts of oestrone-3-sulphate which was used for the standard (7.5-1000 pg/ tube). The assay tubes were incubated at $4^{\circ} \mathrm{C}$ for $2 \mathrm{~h}$. Bound and free steroid were separated by addition of $0.5 \mathrm{ml} \mathrm{charcoal-}$ dextran $(0.5 \%$ charcoal Norit A, $0.05 \%$ dextran in $0.1 \mathrm{M}$-phosphate buffer pH 7.0) during a 15 -min incubation at $4^{\circ} \mathrm{C}$. After centrifugation for $15 \mathrm{~min}$, the supernatant was decanted and mixed with scintillation cocktail and counted for $5 \mathrm{~min}$. The limit of sensitivity of the assay was $7.5 \mathrm{pg} /$ tube and the intra-assay and interassay coefficients of variation based on replicate determinations of a panda urine pool were $5 \cdot 4$ and $13 \cdot 3 \%(n=12)$, respectively. The mean \pm s.e.m. recovery of oestrone sulphate added to a panda urine pool before lyophilization was $95 \cdot 8 \pm 4 \cdot 2(n=12)$.

This conjugated oestrone assay was validated by analysing urine samples obtained during the anoestrous, oestrous and pregnancy phases of the cycle. The samples were hydrolysed with the enzyme, $\beta$-glucuronidase (from Helix pomatia: Sigma Chemical Co., St Louis, MO, U.S.A.), which has both glucuronidase and sulphatase activity and then assayed for oestrogens using an antiserum obtained from Radioassay Systems Laboratories (Carson, CA, U.S.A.). This antiserum shows cross-reactivity against both oestrone and oestradiol. Tritiated oestradiol (sp. act. $120 \mathrm{Ci} /$ $\mathrm{mmol}$ ) was the radioactive tracer and oestradiol $(3 \cdot 12-1000 \mathrm{pg} / \mathrm{tube})$ was the standard. The values that were obtained paralleled the conjugated oestrone values. When these hydrolysates were subject to celite chromatography (Abraham et al., 1975), $>90 \%$ of the oestrogen activity was present in the oestrone fraction. The present results are therefore reported as oestrone. Hodges et al. (1984) have also previously demonstrated that most of the urinary oestrogen is present in the oestrone fraction.

Urinary concentrations of pregnanediol glucuronide were measured by radioimmunoassay using antiserum, standard, and tracer purchased from the Courtauld Institute of Biochemistry (London, U.K.). The antibody to pregnanediol glucuronide was raised in rabbits against $5 \beta$-pregnane- $20 \alpha-$-ol-3 $\alpha$-yl glucuronide-BSA and showed the following cross-reactions: $3.2 \%$ with pregnanediol, $0.05 \%$ with progesterone, $<0.01 \%$ with oestrone-3-glucuronide and oestradiol-17-glucuronide. An unknown component in the urine was found to bind to the antibody. This led to an increase in non-specific binding which resulted in a shift of the standard curve to the right. Therefore, most of the samples were in the non-detectable range unless the values were high, as during pregnancy. The interfering material was eliminated from the lyophilized, reconstituted urine $(100 \mu \mathrm{l})$ by precipitation with $90 \%$ ethanol. After centrifugation at $1800 \mathrm{~g}$ for $5 \mathrm{~min}$, the supernatant was removed, evaporated, and reconstituted in $200 \mu \mathrm{l}$ phosphate-buffered saline ( $\mathrm{pH} 7 \cdot 0,0.9 \% \mathrm{NaCl}, 0.1 \%$ sodium azide, $0 \cdot 1 \%$ gelatin) to be used for the assay. The ethanol-treated urine sample, antibody (1:9000) and $100 \mu \mathrm{l}$ tritiated pregnanediol glucuronide were incubated for $2 \mathrm{~h}$ at $4^{\circ} \mathrm{C}$. The bound and free fractions were separated by the charcoal-dextran procedure as described above.

After ethanol precipitation, samples which were previously undetectable became measurable. Removal of this non-specific binding also resulted in increasing volumes of panda urine giving displacement curves parallel to the standard curve and the recovery of unlabelled pregnanediol glucuronide (64-2000 pg/tube) added to the panda urine was $71 \cdot 3 \pm 3 \cdot 2 \%$. The limit of sensitivity of the assay was $40 \mathrm{pg} /$ tube and the intra-assay and interassay coefficients of variation based on replicate determinations of a panda urine pool were $8 \cdot 3$ and $8 \cdot 5 \%(n=9)$, respectively. Initially, all samples were assayed for pregnanediol glucuronide in 1984 and 1985 so that a time course for pregnancy could be established. However, due to the non-specific binding, the results could not be representative of the actual values. Therefore, after the assay was validated, samples were reassayed when enough urine was present. None of the samples from 1983 was reassayed.

Induction of oestrus. Reproductive activity was induced artificially in the female in June 1985 by administering follicle-stimulating hormone (FSH-P: Burns-Biotec, Omaha, NE, U.S.A.) at a dosage of 5 mg, twice daily i.m. for 
5 days (Days 1-5). On each day of gonadotrophin treatment, FSH was delivered via a pole syringe, the two injections being given at approximately an 8 -h interval. An i.m. injection of 500 i.u. human chorionic gonadotrophin (hCG: Sigma Chemical Co.) was given immediately after the first copulation which occurred on Day 20.

Statistical analysis. Student's $t$ test was used to compare the means of various groups.

\section{Results}

\section{Oestrus and pregnancy}

Natural oestrus occurred at the same time of the year during the first 2 years of this study and the days on which the female mated were almost exactly 1 year apart (18 March 1983 and 19 March 1984). Urinary samples were not obtained on a regular basis in 1983 and the methodological problems associated with low $\mathrm{Cr}$ values and high non-specific binding (pregnanediol glucuronide assay) had not been resolved. The only hormonal pattern noted during the first year was the detectable levels of pregnanediol glucuronide observed during pregnancy (11 June-21 July). In subsequent years, the increase of pregnanediol glucuronide concentration was sudden. The time interval between mating and an increase in the value of this steroid to 3-fold that of the preceding week was 85 and 114 days in 1983 and 1984, respectively. The pregnanediol glucuronide concentration remained elevated for 40 and 26 days until parturition resulting in gestation lengths of 125 and 140 days in 1983 and 1984 respectively.

\section{Oestrone concentrations}

In 1984, there was a marked increase in the excretion of oestrone conjugates associated with a period of pro-oestrus normally characterized by increased activity, vocalization, scent marking, and reduced appetite (Kleiman et al., 1979; Kleiman, 1983). Urinary oestrone concentrations reached a peak of $45 \mathrm{ng} / \mathrm{mg} \mathrm{Cr}$ on 16 March (Fig. 1). Mating occurred on 19 March as the oestrogen values started to decline. Thereafter, oestrone values returned to baseline levels and no major changes were observed through the remainder of pregnancy and parturition on 5 August. In 1985 the animal did not show any of the described behavioural changes and there were no marked elevations in oestrone concentrations during the spring, although mean values from March until June were significantly higher $(P<0.001)$ than the baseline values observed 1 year earlier. Treatment with FSH caused an almost immediate increase in urinary oestrogen excretion and oestrone values rose to $538 \mathrm{ng} / \mathrm{mg}$ Cr on Day 7 (Fig. 2). No signs of behavioural oestrus were observed until almost 9 days after the first FSH injection. During these 9 days, the oestrone concentrations were elevated above pre-FSH treatment concentrations $(P<0.001)$. Subsequently, the female's attractiveness to the male was enhanced and he pursued and mounted her for $>1$ week before the first actual mating occurred 4 times on Days 20-22, concomitantly with the decline in oestrone concentrations.

During oestrus in 1986, urinary concentrations of conjugated oestrone reached a peak value of $118 \mathrm{ng} / \mathrm{mg} \mathrm{Cr}$. The decline in peak levels of oestrogen again coincided with sexual receptivity and attempted mating, but copulation was not achieved.

\section{Pregnanediol glucuronide concentrations}

Before oestrus in 1984, the pregnanediol glucuronide concentrations were very low, increasing significantly $(P<0.001)$ from mean ( \pm s.e.m.) levels of $3.6 \pm 0.9(n=6)$ to $19.3 \pm 1.8(n=22)$ $\mathrm{ng} / \mathrm{mg} \mathrm{Cr}$ after presumed ovulation. They then increased 3 times above post-ovulation concentrations, remained at this level for 3 weeks and then started to decline 1 week before parturition.

In 1985, ovulation was presumably induced by hCG. In mid-October, pregnanediol glucuronide concentrations increased again to $\sim 3$ times the value observed after ovulation (mating to increased pregnanediol glucuronide values $=105-108$ days) and remained high for 4 weeks, similar 


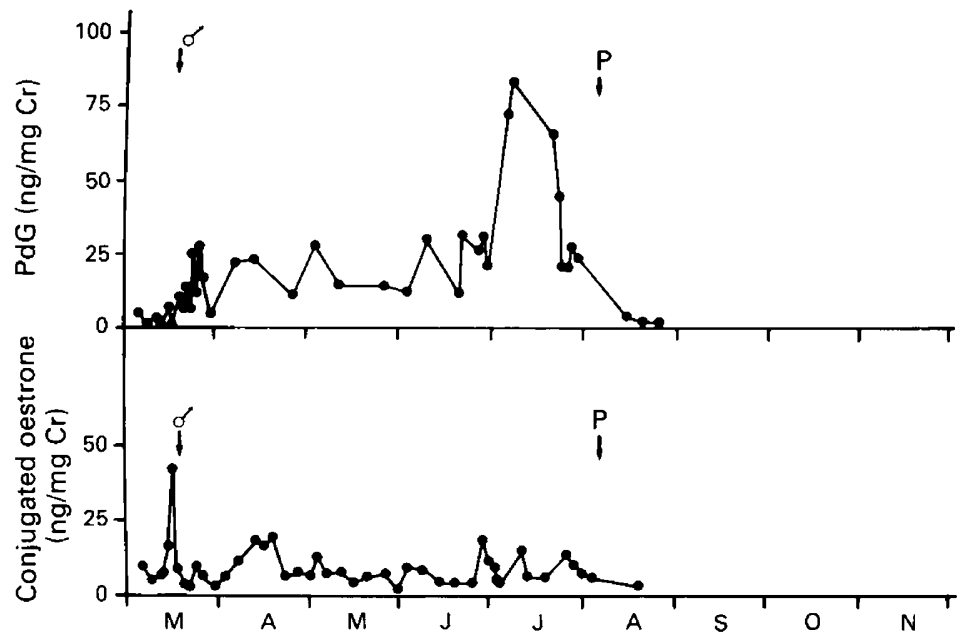

Fig. 1. Urinary concentrations of conjugated oestrone and pregnanediol-3-glucuronide (PdG) in the urine of a giant panda female during oestrus and pregnancy in 1984 . The arrows indicate the day of mating $\left(\delta^{*}\right)$, and the day of parturition $(\mathrm{P})$.

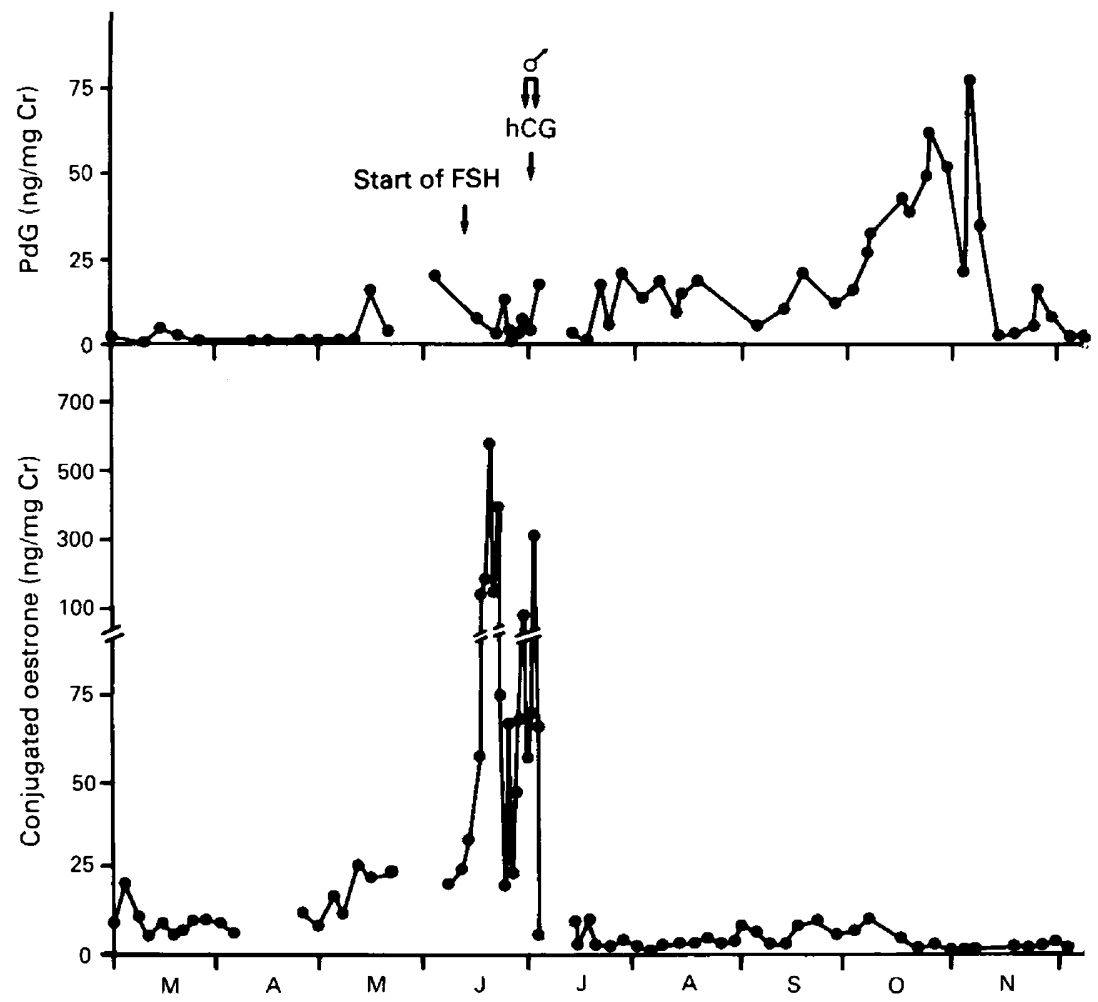

Fig. 2. Urinary concentrations of conjugated oestrone and pregnanediol glucuronide (PdG) in the urine of the giant panda during induced oestrus in 1985. The arrows indicate the days of mating $\left(\xi^{*}\right)$, the day of hCG injection and the day when FSH treatment was started. 
to the observations in the 2 previous years. Behavioural patterns were also similar. For 4 days after the increase in pregnanediol values, the animal had a depressed appetite. Towards the end of November and beginning of December, she exhibited pre-parturition behaviour such as apple cradling and nest-building. However, there was no birth observed in 1985. Subsequently, as the pregnanediol glucuronide values declined, the animal resumed her normal behaviour although the apple cradling persisted.

In the following year, when there was no copulation, there was a luteal rise of pregnanediol glucuronide values that could be indicative of ovulation. These showed wide variations over the 2-week period (12.5-105 $\mathrm{ng} / \mathrm{mg} \mathrm{Cr}$ ) following the oestrone peak.

\section{Discussion}

The present results show a pattern of hormone secretion similar to that reported by Hodges et al. (1984). In all 3 years of observation, there was a sudden dramatic increase in pregnanediol glucuronide levels almost 3 months after copulation. The black bear, which is a species known to exhibit delayed implantation (Wimsatt, 1963) shows a similar pattern of hormone secretion (Foresman \& Daniel, 1983), with progesterone concentrations increasing 2-3-fold at the approximate time of implantation. There has long been disagreement over the phylogeny of the giant panda, whether it should be classified with bears (Ursidae) or raccoons (Procyonidae). Molecular and genetic evidence has shown the panda to be closer phylogenetically to bears than raccoons (O'Brien et al., 1985; Mayr, 1986) and the giant panda could therefore be like bears in exhibiting delayed implantation.

The increased sensitivity of the pregnanediol glucuronide assay also allowed us to follow the pattern of progesterone secretion in this animal after ovulation. Due to difficulties in obtaining urine samples during and after mating, an immediate luteal rise of pregnanediol glucuronide was only observed during the non-conception cycle in 1986. However, in other years (1984-1985), significantly higher concentrations of pregnanediol glucuronide were measured after ovulation, thereby suggesting the presence of an active corpus luteum.

The rise in pregnanediol glucuronide values almost 3-4 months after mating could be a signal of impending implantation. Møller (1973), working with mink (another delayed implanter), used morphological evidence to define the time of implantation and concluded that a rise in progesterone 10 days before implantation as the likely cause for this event. Whether this is the case in the giant panda cannot be deduced from our data. Nevertheless, this species may have a very short period of embryonic growth.

No birth was observed in the 3 rd year of our study although the hormonal pattern of pregnanediol glucuronide secretion after the induced oestrus was the same as during the previous 2 pregnancies. Since experience with this species is so limited, an abortion cannot be excluded since it is not known if there are any external manifestations of abortion. Another possibility is the occurrence of a pseudopregnancy. There is anecdotal information from Chinese zoos that there is a greater incidence of false pregnancies (determined by behavioural observations) when animals are observed to mate in the fall rather than the spring (J. Zheng, personal communication).

Oestrous behaviour in the giant panda occurs when the peak levels of urinary oestrogens begin to decline (Bonney et al., 1982; Hodges et al., 1984). The conjugated oestrone values measured by Hodges et al. (1984) were in the $30-50 \mathrm{ng} / \mathrm{mg}$ Cr range while we measured peak values of 45 and $118 \mathrm{ng} / \mathrm{mg} \mathrm{Cr}$ during the natural oestrous periods of 1984 and 1986. Other carnivores that exhibit increased sexual receptivity in response to decreasing circulating oestrogen concentrations include the wolf (Seal et al., 1979), domestic bitch (Wildt et al., 1979) and mink (Pilbeam et al., 1979). That FSH was effective in inducing reproductive activity in the giant panda was confirmed both by behavioural observations as well as marked increases of conjugated oestrone excretion. The only conclusive way to determine whether or not this treatment induced ovulation other than an actual birth would be a laparotomy. However, only non-invasive methods were available and the 
hormonal data do suggest that ovulation was induced. Among other carnivores, lions have been induced to ovulate by injections with PMSG followed by treatment with hCG (Rowlands \& Sadleir, 1968) and serial injections of FSH have induced follicle development in some species of felids (Wildt et al., 1978, 1981).

The observations reported in this study substantiate and provide additional information on the reproductive biology of the giant panda that may aid in conservation efforts of this species. The additional information on the time intervals observed between mating, rise in pregnanediol glucuronide and parturition should help in the management of this animal and in fact was useful in predicting a panda birth in 1987 (D. G. Kleiman, M. Chaudhuri, S. Monfort, unpublished data). The results of the gonadotrophin stimulation also demonstrate that oestrus and presumably ovulation can be induced in this species.

We thank Ms Emilee Carrasco for technical assistance; Dr D. C. Collins for the antiserum to the conjugated oestrogens; the keepers B. Bingham, M. Connery, E. Jacobs and N. Clevenger for assistance in collecting urine; and $\mathrm{N}$. Ball for help with behavioural observations. This study was supported by a grant from the Jessie Smith Noyes Foundation.

\section{References}

Abraham, G.E., Manlimos, F.S., Solis, F.M. \& Wickman, C. (1975) Combined radioimmunoassay of four steroids in one $\mathrm{ml}$ of plasma: androgens. Clin. Biochem. 8, 374-378.

Anon, (1974) On the breeding of the giant panda and the development of its cubs. Acta zool. Sin. 20, 139-147.

Bonney, R.C., Wood, D.J. \& Kleiman, D.G. (1982) Endocrine correlates of behavioural oestrus in the female giant panda (Ailuropoda melanoleuca) and associated hormonal changes in the male. J. Reprod. Fert. 64, 209-215.

Foresman, K.R. \& Daniel, J.C. (1983) Plasma progesterone concentrations in pregnant and nonpregnant black bears. J. Reprod. Fert. 68, 235-239.

Hodges, J.K., Bevan, D.J., Celma, M., Hearn, J.P., Jones, D.M., Kleiman, D.G., Knight, J.A. \& Moore, H.D.M. (1984) Aspects of the reproductive endocrinology of the female giant panda (Ailuropoda melanoleuca) with special reference to the detection of ovulation and pregnancy. J. Zool., Lond 203, 253-267.

Kleiman, D.G. (1983) Ethology and reproduction of captive giant pandas (Ailuropoda melanoleuca), $Z$. Tierpsychol. 62, 1-46.

Kleiman, D.G., Karesh, W.B. \& Chu, P.R. (1979) Behavioural changes associated with oestrus in the giant panda (Ailuropoda melanoleuca) with comments on female proceptive behaviour. Int. Zoo Yb. 19, 217-223.

Mayr, E. (1986) Uncertainty in science: is the giant panda a bear or a raccoon? Nature, Lond 323, 769-771.

Moller, O.M. (1973) The progesterone concentrations in the peripheral plasma of the mink (Mustela vison) during pregnancy. $J$. Endocr. 56, 121-132.

O'Brien, S.J., Nash, W.G., Wildt, D.E., Bush, M.E. \& Benveniste, R.E. (1985) A molecular solution to the riddle of the giant panda's phylogeny. Nature, Lond. 317, 140-144.
Pilbeam, T.E., Concannon, P.W. \& Travis, H.F. (1979) The annual reproductive cycle of mink (Mustela vison). J. Anim. Sci. 48, 578-584.

Rowlands, I.W. \& Sadleir, R.M.F.S. (1968) Induction of ovulation in the lion, Panthera leo. J. Reprod. Fert. 16, 105-111.

Schaller, G.B., Hu, J., Pan, W. \& Zhu, J. (1985) The Giant Pandas of Wolong. University of Chicago Press, Chicago.

Seal, U.S., Plotka, E.D., Packard, J.M. \& Mech, L.D. (1979) Endocrine correlates of reproduction in the wolf. 1. Serum progesterone, estradiol and LH during the estrous cycle. Biol. Reprod. 21, 1057-1066.

Shideler, S.E., Czekala, N.M., Kasman, L.H., Lindburg, D.G. \& Lasley, B.L. (1983) Monitoring ovulation and implantation in the lion-tailed macaque (Macacca silenus) through urinary estrone conjugate evaluations. Biol. Reprod. 29, 905-911.

Taussky, H.H. (1954) A microcolorimetric determination of creatinine in urine by the Jaffe reaction. J. biol. Chem. 208, 53-61.

Wildt, D.E., Kinney, G.M. \& Seager, S.W.J. (1978) Gonadotropin induced reproductive cyclicity in the domestic cat. Lab. Anim. Sci. 28, 301-307.

Wildt, D.E., Danko, W.B., Chakraborty, P.K. \& Seager, S.W.J. (1979) Relationship of serum estrone, estradiol-17ß and progesterone to $\mathrm{LH}$, sexual behavior and time of ovulation in the bitch. Biol. Reprod. 20, 648-658.

Wildt, D.E., Platz, C.C., Seager, S.W.J. \& Bush, M. (1981) Induction of ovarian activity in the cheetah (Acinonyx jubatus). Biol. Reprod. 24, 217-222.

Wimsatt, W.A. (1963) Delayed implantation in the Ursidae with particular reference to the black bear (Ursus americanus, Pallas). In Delayed Implantation, pp. 49-86. Ed. A. C. Enders. University of Chicago Press, Chicago.

Received 2 October 1987 